\title{
El universo o ¿la Biblioteca de Babel?*
}

\section{Hortensia Cuéllar Universidad Panamericana}

This article is a philosophical reflection about one of the most important Borges' narration: "La Biblioteca de Babel" (Babel's Library), where he set up some problems about the UniverseLibrary, the time and the eternity, the possible and the impossible, the phantasy and the reality, etc. That story lets us catch a glimpse on the analogical work underlying in its intimate structure.

Uno de los más célebres cuentos de Jorge Luis Borges es La Biblioteca de Babel, escrito en 1941, cuando el poeta tenia 42 años. Se trata - por su parte- de una narración donde combina la fantasía literaria, la lucubración filosófica y tangencialmente la teología. Se trata - por mi parte— de un trabajo de análisis donde pretendo demostrar que el acceso a Dios a través de los libros (al menos de algunos libros) y del conocimiento del universo no le resultaba ajeno. Con ello no quiero sostener que su propuesta sea una transferencia literaria de las llamadas vías cosmológicas de la demostración de la existencia de Dios, sino simplemente apuntar que dentro del universo borgiano, el tema de Dios fue trasfondo de algunas de sus más importantes controversias filosóficas y teológicas.

No desconozco que Borges es ante todo una de las cumbres de la literatura del siglo XX. Ello, sin embargo, no excluye que su genialidad poética y metafisica le llevara a hurgar de manera

\footnotetext{
*Para Rocío Mier y Terán y Liliana Alvarez Tostado con mi reconocimiento y afecto.
} 
insistente, en multitud de temáticas que por su importancia, trascienden las fronteras de la creatividad literaria, para inscribirse en un horizonte metalinguístico que le condujo a crear uno de los lenguajes metafóricos más exquisitos de nuestros días, mediante el cual dio cauce abierto a su pensamiento. $Y$ la metáfora - recordémoslo- es analogía, es comparación, es —en este casorealidad $\mathrm{y}$ ficción, lenguaje $\mathrm{y}$ pensamiento vivo, que quiere comunicarnos o ponernos en contacto, con un determinado tipo de realidad no fácilmente asible en palabras. Es esta una de las claves del trabajo de Borges: crear, inventar, descubrir analogías traducibles en metáforas, que discurren en el espacio-tiempo del poeta y escritor argentino, pero que no se anclan allí sino que por su especifica virtualidad de expresadoras de realidad (de diferentes tipos de realidad) trascienden el hic et nunc especifico de la narración concreta, para instalarse - de algún modo- en el acervo perenne de la literatura y pensamiento universal.

Este cuento -me parece- es un claro ejemplo del uso de las analogías al plantear el problema del universo-Biblioteca que con su multitud de anaqueles y galerias le conducen a pensar en la posibilidad de un libro total que encierre todos los secretos del universo y pueda ser leido por algún hombre - al menos por unopara que la enorme biblioteca se justifique. ¿Se justifique para quién o en atención a quién? Es esa una de las interrogaciones de fondo que intentaremos contestar.

¿Cómo comienza el cuento? "El universo (que otros llaman Biblioteca) se compone de un numero indefinido y tal vez infinito de galerías hexagonales, con vastos pozos de ventilación en el medio, cercados por barandas bajísimas"l. ¿Qué quería decir con ésto? ¿Qué

1 Jorge Luis BoRges: "La Biblioteca de Babel", Obras Completas (1923-1949) -que citaré en adelante con las siglas $O C$ - - Buenos Aires: Emecé Editores 1994, p. 465. Lo que aqui presento constituye una exégesis de una de las posibles lecturas que admiten una narración así. Algún lector crítico puede argumentarme que un enfoque asi es cuestionable. Puedo responderle que en la literatura de Borges solamente está excluido lo imposible, con lo cual es posible abordar su lectura bajo una de las múltiples facetas que la misma lectura sugiera al lector, sin dejar de lado 
historia fantástica nos iba a narrar? ¿Qué inquietud poéticoexistencial iria a desarrollar en "La Biblioteca de Babel"?

Una clave importante se encuentra ya en esa frase del comienzo: "El universo (que otros llaman Biblioteca) se compone de un número indefinido y tal vez infinito de galerias hexagonales...", idea que implica otras más, entre ellas, que no se trata de un universo cerrado, finito, monádico, sino de algo que puede ser infinito, variado $\mathrm{e}$ indefinido o - como también dice Borges renglones más abajointerminable ${ }^{2}$. Tal Biblioteca-universo no permanece ignorada (si así fuera, no podriamos plantearnos siquiera la existencia del cuento) sino que es conocida por los hombres a través de "un espejo que duplica fielmente las apariencias"3; ¿cuáles?, las que los hombres pueden descubrir mirando al espejo que les impulsa a inferir -al menos a muchos de ellos- que la Biblioteca-universo no es infinita sino limitada porque puede ser reflejada en el espejo ("si lo fuera realmente ¿a qué esa duplicación ilusoria?"). Y es que la noción de infinito $\longrightarrow$ para este tipo de observadores - no puede ser recogida 0 "duplicada" en un espejo, ya que de suyo - tal noción- sugiere ilimitación, falta de fronteras, con lo cual, al duplicarse, se plantea la paradoje de la infinitud del universo

La existencia del espejo, sin embargo, resulta necesaria para acceder a la realidad allende al espejo (por su mediación la conocemos), con lo cual la metáfora del espejo en la fantasía creativa de Borges $^{4}$ vuelve a adquirir un lugar preponderante para hecernos conocer la realidad ad-extra al espejo. ¿De qué modo? De manera reflejada, puesto que se trata de un espejo. Con ello quiero decir que el espejo en su narración, es una figura simbólica "a través de la

los textos de Borges. Me parece que en el caso de nuestro autor no es pertinente hablar de una interpretación canónica: caben diversas lecturas.

2 J. L. BORGES: "La Biblioteca de Babel"..., p. 465.

3 J. L. Borges: "La Biblioteca de Babel"..., p. 465.

4 Por cierto, no es este el único lugar donde también emplea esta imagen. Se trata de una de sus metáforas favoritas. Cfr. El Aleph; El Zahir, El espejo y la máscara; Tlön, Uqbar, Orbis Tertius; Los espejos abominables, etc. 
cual" y en su lenguaje poético "prefiere soñar que las superficies bruñidas figuran y prometen el universo"s.

Esta expresión "las superficies bruñidas figuran..." encierra múltiples virtualidades entre las que se encuentran las siguientes: a) de manera inmediata viene a indicarnos que a través del reflejo del espejo conocemos el universo. b) En otro sentido, y realizando una exégesis que toma como antecedente la teoría de la figuración de Wittgenstein, "figurar" (abbilden) implica "posibilidad de darse y no darse efectivos estados de cosas"6. Aplicado a Borges, podemos aventurar que la frase "figurar y prometer el universo" abre la posibilidad — muy de acuerdo a su narrativa poético-metafisica- de entroncar - por algún camino- con la infinitud del universo, sea real o literario. Parece evidente que el contexto borgiano se mueve sobre todo en las coordenadas del segundo tipo de universo, pero no olvidemos que - aún ocurriendo así- a través del uso de metáforas podemos "descubrir" algo más en su narrativa. Esto es la posibilidad siempre abierta de dar-se a la existencia, de surgir a la existencia, de indicar existencia, en un libro escrito por Borges. c) En un tercer sentido, el espejo puede significarnos el trabajo operativo de las diversas facultades cognoscitivas humanas: en particular la inteligencia ${ }^{7}$ que especula $o$ refleja intrarracionalmente lo que

\footnotetext{
5 J. L. Borges: "La Biblioteca de Babel".., p. 465.

${ }^{6} \mathrm{El}$ texto de Wittgenstein es el siguiente: "La figura figura la realidad en la medida en que representa una posiblidad de darse y no darse efectivos estados de cosas" (Das Bild bildet die Wirklichkeit ab, indem es eine Möglichkeit des Bestehens und Nichtbestehens von Sachverhalten darstellt), (Tractatus logico-philosophicus, 2.201). Otro más: "La figura representa lo que representa, independientemente de su verdad o falsedad, por la forma de la figuración" (Das Bild stellt dar, was es darstellt, unabhängig von seiner Wahr-oder Falschheit, durch die Form der Abbildung), (Tractatus logico-philosophicus, 2.22).

${ }^{7}$ El testimonio de Marguerite YouRCENAR en este sentido me parece importante. En su última conferencia dictada en Harvard en octubre de 1987 llamó a Borges le voyant (el vidente) porque a diferencia del visionario, Borges miraba las cosas "con una mirada interior ayudado por los recuerdos almacenados por sus ojos de antaño, reforzada quizá con los recuerdos ancestrales de hombres que vieron antes que él, capaz de añadir a esta visión lo que la inteligencia (la inteligencia más que la imaginación) le aporta" (Peregrina y Extranjera, trad. de Emma Calatayud, Madrid: Alfaguara 1992, p. 259).
} 
intelige para hacernos conocer la realidad, aportando además con el auxilio de la memoria y la imaginación, todo el trabajo creativo de que es capaz el hombre inventivo.

Observada la tarea del espejo desde un enfoque distinto, su nivel de operación se circunscribiría únicamente a "lo percibido" en el reflejo, a la imagen recogida en el espejo, sin una mayor indagación o trabajo de intelección o análisis. En esta última opción se inscribe toda la tradición empirista de la que paradójicamente Borges es un poco deudor ${ }^{8}$. De alli tal vez su dificultad especulativa para aclararse a sí mismo diversos problemas metafisicos, como es el caso de la eternidad y el tiempo y de la existencia divina.

Lo que sí queda claro en el horizonte borgiano es que "El universo-Biblioteca" se encuentra alli para ser consultado a través de alguno de sus inumerables libros. Para ello, no es necesaria la luz que proviene del sol o de alguna otra estrella, sino "de unas frutas esféricas que llevan el nombre de lámparas" que emiten una luz insuficiente aunque si incesante" ${ }^{\prime \prime}$ ¿Estará refiriéndose nuevamente a algunas de las facultades cognoscitivas humanas anteriormente mencionadas ${ }^{10}$, limitadas en su operación pero siempre necesarias?

En su narración, la comprensión de las salas hexagonales encierra asimismo un simbolismo que viene a señalarnos algún tipo de existencia que no es la oquedad sin sentido de lo vacio, sino -con los idealistas- la condición de posibilidad de los objetos $\mathrm{y}$, por lo

8 J. L. Borges, en "Utopía de un hombre que está cansado", afirma: "Esse est percipi (ser es ser retratado) era el principio, el medio y el fin de nuestro singular concepto del mundo", en Gran Colección de la Literatura Universal (Latinoamericana II), México: Gallimard/Promexa 1982, p. 221. Ver tambièn: "El tiempo circular", "Historia de la etemidad", etc.

9 J. L. BORGES: "Utopia..., p. 221. El subrayado es mío.

${ }^{10} \mathrm{Se}$ trata de un gran narrador que reiteradamente rememora sus recuerdos, pero no solamente eso, sino que les da vida a través de su genio poético y literario. Y el genio - - expresión de Kant- es esa rara mixtura entre el talento o disposición natural del artista y las reglas del arte, que da origen a la obra de arte. De él solamente gozan algunos elegidos. Borges fue uno de ellos. El oráculo desde antes de su nacimiento, asi lo había anunciado. 
tanto, de su existencia. He aqui las palabras de Borges: “(...) los idealistas arguyen que las salas hexagonales son una forma necesaria del espacio absoluto o por lo menos de nuestra intuición del espacio"11; es esta una remembranza de la doctrina del filósofo de Königsberg, para quien el espacio y el tiempo constituian las formas apriori ( $\mathrm{y}$ por tanto necesarias) de nuestra sensibilidad ${ }^{12}$. De ahi que las salas hexagonales, con su multitud de anaqueles y libros, resultarian perentorias.

Otros observadores del cielo - Borges alude aqui a los místicospueden descubrir, al mirar el universo: "una cámara circular con un gran libro circular de lomo contínuo, que da toda la vuelta de las paredes; pero su testimonio es sospechoso; sus palabras oscuras. Ese libro cíclico es Dios"13. En este lenguaje simbólico está plasmando dos ideas importantes: a) el tema del círculo como figura perfecta que puede conducirnos a cualquier parte, pero al mismo tiempo $\longrightarrow$ si insistimos en rondar su circularidad-a ningún lugar concreto $\mathrm{y}, \mathrm{b}$ ) habla de la realidad más excelsa, que es la realidad de Dios: "ese libro cíclico es Dios". Ambos temas son recurrentes a lo largo de su obra -más el primero que el segundo- y se perfilan como el trasfondo conceptual de algunas de sus más relevantes controversias metafisicas y teológicas. Lo prueban las distintas lecturas que sobre el pensamiento de Nietzsche realiza a lo largo de su vida ${ }^{14}$, donde rememora la doctrina del eterno retorno y la circularidad sin fin a la

\section{J. L. BORgES: "Utopia..., p. 221.}

$12 \mathrm{Cfr}$. I. KANT: $K r V, \mathrm{~A} 24 ; \mathrm{B} 39$. El texto es el siguiente: "Se considerará, pues el espacio, como la condición de posibilidad de los fenómenos y no como una determinación independiente de ellos; es una representación a priori, fundamento necesario de los fenómenos extemos" (Er wird also als die Bedingung der Möglichkeit der Erscheinungen und nicht als eine von ihnen abhängende Bestimmung angefehen und ist eine Worstellung a priori, bei nothwendiger Weise ausseren Erscheinungen zum Grunde liegt).

13 J. L. BORGES: "La Biblioteca de Babel"..., p. 466.

14 Por ejemplo "La doctrina de los ciclos" fechada en 1934 y publicada en Sur o "Algunos pareceres sobre Nietzsche" publicada en La Nación en 1940. Esto con independencia de las constantes referencias que hace a nivel de presupuestos teórico-filosóficos en narraciones tan importantes como "La historia de la eternidad", "Nueva refutación del tiempo", etc. 
que conduce si se circunscriben sus tesis, así como su inquietante interés en "la historia de la eternidad" que le lleva a discutir el problema del tiempo como un problema metafísico que entronca con la pregunta por la eternidad. Estas son sus palabras: "El tiempo es un problema para nosotros, un tenebroso y exigente problema, acaso el más vital de la metafisica; la eternidad, un juego o una fatigada esperanza"15. En La Biblioteca de Babel expresa: "(...) el universo brúscamente usurpó las dimensiones ilimitadas de la esperanza"16.

De la respuesta que se de a estos planteamientos, depende la creencia o no en Dios. Borges lo sabía bien, pero sus respuestas o posicionamientos vitales ante este asunto tan importante, recibieron diferente tratamiento; gran parte de éste envuelto en la ironía, como sostiene Emir Rodríguez Monegal en su estudio sobre Borges ${ }^{17}$. De aquí que el testimonio de los místicos en su comprensión o referencia al universo, le resulte sospechoso y sus palabras oscuras porque no permiten vislumbrar, desde su propio relato y en este lugar concreto, alguna nota más acerca de esa "Biblioteca"; pero sí de ese gran libro circular - Dios- que parece encontrarse en todas partes porque "da toda la vuelta de las paredes": ¿habla de omnipresencia?, ¿más bien proyecta su multinombrado panteísmo? El lenguaje poético, sin embargo, nos resulta evanescente.

Ciertamente, por otro lado, él prefiere pensar que la "Biblioteca" es infinita, interminable, periódica, incluso podria decirse "sin fin", y siempre atrayente. Veamos los textos siguientes:

"Básteme, por ahora, repetir el dictamen clásico: La Biblioteca es una esfera cuyo centro cabal es cualquier hexágono, cuya circunferencia es inaccesible"18.

15. En "Historia de la etemidad", $O C$ I, p. 353.

16 J. L. BORGES: "La Biblioteca de Babel"..., p.466.

${ }^{17}$ Cfr. Jorge Luis Borges. Ficcionario (Una antología de sus textos), ed., intr., prol. y nts. por Emir Rodriguez Monegal, México: FCE 1997, p. 433.

18 J. L. Borges: "La Biblioteca de Babel”..., p. 466. 
En otro lugar escribe: "La Biblioteca es tan enorme que toda reducción de origen humano resulta infinitesimal"19.

Y en un texto más, de claro perfil autobiográfico, afirma: "Quizá me engañen la vejez y el temor, pero sospecho que la especie humana - la única- está por extinguirse y que la Biblioteca perdurará: iluminada, solitaria, infinita, perfectamente inmóvil, armada de volúmenes preciosos, inútil, incompleta, secreta.

Acabo de escribir infinita. No he interpolado ese adjetivo por una costumbre retórica; digo que no es ilógico pensar que el mundo es infinito ${ }^{20}$. Quienes lo juzgan limitado, postulan que en lugares remotos los corredores y las escaleras y hexágonos pueden inconcebiblemente cesar - lo cual es absurdo. Quienes lo imaginan sin límites, olvidan que los tiene el número posible de libros. Yo me atrevo a insinuar esta solución del antiguo problema: es La Biblioteca ilimitada y periódica. Si un eterno viajero la atravesara en cualquier dirección, comprobaría al cabo de los siglos que los mismos volúmenes se repiten en el mismo desorden (que, repetido, sería un orden: el Orden). Mi soledad se alegra con esa elegante esperanza ${ }^{21}$.

Aqui destacan otras ideas importantes: en primer lugar, Borges juega con la mixtura de ficción y realidad, sus recuerdos con su imaginación, volviendo a recurrir a la analogía: "Acabo de escribir infinita. No he interpolado ese adjetivo por una costumbre retórica; digo que no es ilógico pensar que el mundo es infinito. Quienes lo imaginan sin límites, olvidan que los tiene el número posible de libros". Mundo-Biblioteca-libros-infinitud-finitud: conceptosrealidad que merecen la atención de Borges. ¿Qué podemos decir al respecto? No demaciado, pero atendiendo al proceso discursivo de su narración, para tratar de clarificar un poco la analogía, nos apoyaremos en dos de los más eminentes filósofos clásicos de la historia - Aristóteles y Tomás de Aquino- por sus consideraciones

\footnotetext{
19 J. L. BORGES: "La Biblioteca de Babel"..., p. 469.

${ }^{20} \mathrm{El}$ subrayado es mío.

${ }^{21}$ Cfr. J. L. BoRges: "La Biblioteca de Babel"..., p. 471.
} 
en torno a temas de filosofia de la naturaleza y metafisica. Puede ser cuestionable su elección, pero aquí también pregunto: ¿Acaso no es posible en filosofia elegir como maestros o puntos de referencia a quienes mucho tienen aún qué decir? Solamente basta poner un poco de atención y dialogar con ellos.

Borges ha dicho que la "Biblioteca" es infinita, ¿qué quiere decir con ésto? Si atendemos al sentido de los términos, la noción de infinitud implica en palabras del Filósofo, falta de fronteras o limites, desbordamiento que abre y no termina: "Aquello más allá de lo cual hay siempre algo"22. Otro texto básico para abordar el problema es el de Met. XI, 1066a 35-40 donde sostiene: "Infinito es o bien lo que no puede ser recorrido porque su naturaleza no lo permite (...) o bien lo que sólo puede ser recorrido de manera incompleta, o que apenas puede serlo, o lo que no puede ser recorrido ni limitado aunque por su naturaleza pudiera serlo". Aquí está hablando de algunos de los sentidos que tiene la expresión "infinito": inicialmente del infinito que no encierra magnitud porque "no puede ser recorrido" (¿estará hablando de un infinito en sí?); enseguida, de otros sentidos que sí tienen que ver con la medida o el lugar; finalmente trata de otro sentido distinto "que no puede ser recorrido ni limitado aunque por su naturaleza pudiera serlo" (¿se referirá al infinito matemático?).

Aristóteles no responde y solamente afirma que "el infinito no puede existir en acto" y esto es "evidente" ${ }^{23}$. ¿Existe entonces en potencia? Mucho habría qué indagar para revisar este aspecto que - como casi todo en el filósofo griego- tiene que ver con el polajós legetai y la analogía ${ }^{24}$, con lo cual, dependiendo del sentido y el contexto, lo "infinito" puede decirse en algunos casos en potencia (por ejemplo: lo infinito por adición) y en otros, en acto, con una actualidad sui generis (por ejemplo: el infinito pensado), independientemente de que los principales sentidos de infinito

22 Cír. ARISTÓteles: Fisica, III, 6, 207a 1. Para un acercamiento más profundo y amplio del problema cfr. Fisica, III, 4a 8.

23 Cfr. ARISTÓteles: Met., XI, 1066 b, 11-12.

24 Cfr. ARISTÓteles: Met., IV y Fisica, III. 
—según Aristóteles- los podemos encontrar en el ámbito de las ciencias de la naturaleza que se ocupan de magnitudes, movimiento y tiempo. En los tres casos "lo infinito se entiende evidentemente de forma diferente" 25 .

Desde una perspectiva ampliada, más acorde a nuestros intereses y sin transgredir límites categoriales - simplemente se trata de una visión metafisica-, cabe la posibilidad de plantear la pregunta por la infinitud del universo, pero no del matemático o literario, sino la del real. ¿Es actual? ¿Es potencial? Evidentemente, con lo dicho en párrafos precedentes, ninguna de las dos opciones prospera, ya que ni está totalmente en acto ni tampoco es pura potencia, es una mixtura en virtud de su condición creatural, asunto que no trabaja el Filósofo, pero si uno de sus discípulos: Santo Tomás de Aquino. Para encuadrar el problema el Aquinate sostiene que la noción de "infinito" tiene que ser estudiada al menos desde dos ángulos radicales: en sentido absoluto y en sentido relativo ${ }^{26}$. En sentido absoluto solamente puede decirse de Dios, que posee como uno de sus atributos la infinitud y por lo mismo se identifica con Él. En sentido relativo lo que se dice "infinito" lo es a parte rei, es decir, por analogía. Encierra potencia ${ }^{27}$. Corresponderia, por ende, a cualquiera de los sentidos trabajados por el Estagirita en Metafisica $\mathrm{XI}$

Aplicado a Borges, el sentido de la Biblioteca-universo deberá ser relativo en virtud de que, de manera absoluta, "infinito" sólo puede decirse de Dios y el universo visto bajo cualquier óptica, incluyendo la metafórico-poética del escritor argentino, no es Dios sino una interpretación que puede coincidir o no con lo existente. Para Borges esa idea es clara puesto que le lleva a sostener que "(...) quienes lo imaginan sin límites, olvidan que los tiene el número posible de libros", esto es, tiene límites, con lo cual las galerias y anaqueles también lo son dentro de la no limitación e infinitud del universo,

${ }^{25}$ Cfr. ARISTóteles: Fisica, III, 6, 206a 27.

${ }^{26}$ Cfr. S. T. AQuino: S. Th., I, q. 7.

${ }^{27}$ Cfr. S. T. Aquino: $S$. Th., I, q. 7. 
dichas estas nociones con las precisiones señaladas anteriormente (es decir, en sentido relativo).

El fundamento de este argumento es aún más profundo, ya que según el dictamen clásico: "Al concepto de criatura se opone que su esencia se identifique con su ser, porque el ser subsistente no es un ser creado, y por esto es incompatible con la esencia del ser creado que sea infinito en absoluto. El caso de Dios es distinto en virtud de su subsistencia no originada y perfecta. Mas no por ello (por ejemplo cuando se plantea el tema de sus atributos, entre ellos el de su potencia infinita) se indica que aun lo imposible sea objeto de su poder vg. hacer que la criatura sea infinita en absoluto o el círculo sea cuadrado. Estos ejemplos encierran una patente contradictio no sólo in terminis sino en esencia, con lo cual de suyo son imposibles de realización. A este respecto el Aquinate afirma: “(...) aunque Dios tenga poder infinito, no puede, sin embargo, hacer que una criatura no sea criatura (esto valdría tanto como sostener la existencia simultánea de los contradictorios) y por lo tanto no puede haber una cosa absolutamente infinita"28.

¿Qué ocurre entonces con la tesis borgiana de que la "Biblioteca" es infinita, ilimitada y periódica? Si intentamos responder a la cuestión desde la fisica, es posible que no encontremos una respuesta adecuada. Si lo intentamos desde la metafisica, como su planteamiento es radical, tendriamos que partir de la consideración: absoluto y relativo, que permite una mayor movilidad ontológicoconceptual, con lo cual la interrogante inicial encuentra respuesta: la Biblioteca-universo borgiana tanto en su sentido literario como en una posible apertura analógica al ámbito de lo real, se inscriben en el sentido relativo de expresar absoluto. Así parece reflejarlo Borges cuando afirma que "En efecto, la Biblioteca incluye todas las estructuras verbales, todas las variaciones que permiten los vienticinco símbolos ortográficos, pero no un solo disparate absoluto"29.

${ }^{28}$ Cfr. S. T. Aquino: S. Th., I, q. 7, a. 2, sol.

29 J. L. Borges: "La Biblioteca de Babel"..., p. 470. 
Al sostener, además, que la "Biblioteca" es periódica, introduce la noción de tiempo (lo temporal encierra sucesión, periodicidad) que implica limitación, instante, además de pasado, presente y futuro en contínuo devenir - ¿acaso no el futuro de mañana en dos días más ya pasó?). De allí tal vez la metáfora de que si un eterno viajero la atravesara en cualquier dirección, comprobaria al cabo de los siglos que los mismos volúmenes se repiten en el mismo desorden (caos) que paradójicamente encierran un cierto orden que viene a ser el "Orden Universal" u orden del universo que, asimismo, le resulta interminable, infinito. En esta tesis se adivina de nueva cuenta la doctrina del eterno retorno que resultándole tan querida no deja, asimismo, de despertarle diversas oscuridades y paradojas (no es este el momento de hacer una referencia más amplia a ellas); simplemente traeré a colación dos importantes objeciones que hace Borges a la hipótesis de la circularidad del tiempo. La primera corresponde a "La doctrina de los ciclos", la segunda a "El tiempo circular":

1) "Una certidumbre final, esta vez de orden metafísico. Aceptada la tesis de Zarathustra, no acabo de entender como dos procesos idénticos dejan de aglomerarse en uno. ¿Basta la mera sucesión, no verificada por nadie? A falta de un arcángel especial que lleve la cuenta, qué significa el hecho de que atravesemos el ciclo trece mil quinientos catorce, y no el primero de la serie o el número trescientos veintidós con el exponente dos mil? Nada, para la práctica - lo que daña al pensador. Nada, para la inteligencia - lo cual ya es grave" 30 .

2) "Arribo al tercer modo de interpretar las eternas repeticiones: el menos melodramático, pero también el único imaginable. Quiero decir la concepción de los ciclos similares, no idénticos. Imposible formar el catálogo infinito de autoridades: pienso en los días y las noches de Brahma; en los períodos cuyo inmóvil reloj es una pirámide (...); en los hombres de Hesíodo, que degeneran desde el oro hasta el

30 J. L. BORGES: "La doctrina de los ciclos", OC I, p. 391. 
hierro; (...) en Spengler y en Vico; en Schopenhauer, en Emerson; en los First Principles de Spencer y en Eureka de Poe (...) De tal profusión de testimonios básteme copiar uno, de Marco Aurelio: "'Aunque los años de tu vida fueren tres mil o diez veces tres, recuerda que ninguno pierde otra vida que la que vive ahora, ni vive otra vida que la que pierde. (...) El presente es de todos; morir es perder el presente, que es un lapso brevísimo. Nadie pierde el pasado ni el porvenir, pues a nadie pueden quitarle lo que no tiene. Recuerda que todas las cosas giran y vuelven a girar por las mismas órbitas y que para que el espectador es igual verlas un siglo o infinitamente" (Reflexiones, 14) ${ }^{31}$.

El comentario de Borges a este significativo texto va en este tenor:

"Marco Aurelio afirma la analogía, no la identidad, de los muchos destinos individuales. Afirma que cualquier lapso -un siglo, un año, una sola noche, tal vez el inasible presente- contiene integramente la historia. En su forma extrema esa conjetura es de fácil refutación: un sabor difiere de otro sabor, diez minutos de dolor físico no equivalen a diez minutos de álgebra. Aplicada a grandes períodos, a los setenta años de edad que el Libro de los Salmos nos adjudica, la conjetura es verosimil o tolerable. Se reduce a afirmar que el número de percepciones, de emociones, de pensamientos, de vicisitudes humanas, es limitado, y que antes de la muerte lo agotaremos"32.

No obstante estas acotaciones, reitera su concepción de la interminabiliad e infinitud del universo. He aquí el texto:

"Como todos los hombres de la Biblioteca, he viajado en mi juventud; he peregrinado en busca de un libro, acaso del catálogo de catálogos; ahora que mis ojos casi no pueden descifrar lo que escribo, me preparo a morir a unas pocas leguas del hexágono en que

31 J. L. BORGES: "El tiempo circular", OC I, p. 394.

32 J. L. BoRGES: "El tiempo circular",,.., p. 395. 
nací. Muerto no faltarán manos piadosas que me tiren de la baranda; mi sepultura será el aire insondable: mi cuerpo se hundirá largamente y se corromperá y disolverá en el viento engendrado por la caída, que es infinita. Yo afirmo que la Biblioteca es interminable" 33 .

La "Biblioteca" en su narración, además de interminable, "es una esfera cuyo centro cabal es cualquier hexágono, cuya circunferencia es inaccesible"34. Así vuelve a mencionar esa figura perfecta e infinita que se encuentra allí con toda su riqueza, sin pretender señalar ningún lugar preciso como su centro peculiar. Cualquier lugar del universo le resulta importante. Mas cabe la salvedad de que solamente el hombre es capaz de "leer" en el espejo. A este propósito, encontramos en La Biblioteca de Babel un texto paradigmático que recoge y apoya la idea precedente:

"No me parece inverosímil que en algún anaquel del universo haya un libro total; ruego a los dioses ignorados que un hombre - juno solo, aunque sea, hace miles de años! - lo haya examinado y leído. Si el honor y la sabiduría y la felicidad no son para mi, que sean para otros. Que el cielo exista aunque mi lugar sea el infierno. Que yo sea ultrajado y aniquilado, pero que en un instante, en un ser, $T u$ enorme Biblioteca se justifique" 35 .

Y se justifique desde la pretensión de ser conocida o mejor "leída" por un hombre - cualquier hombre- sea de donde fuere. Lo importante es que ante él (o ante muchos como él) los secretos ignorados del universo puedan ser develados y examinados a fin de pehetrar en sus arcanos secretos. La pretensión es posible porque para Borges - apoyándose en una noción modal vertebradora de gran parte del pensamiento occidental moderno (Leibniz, Kant, Hegel, Kierkegaard, Sartre, Wittgenstein, etc.)— “(..) basta que un

33 J. L. Borges: "La Biblioteca de Babel".., p. 465.

34 J. L. Borges: "La Biblioteca de Babel".., p. 466.

35 J. L. Borges: "La Biblioteca de Babel".., pp. 469-470. El subrayado es mío. ¿A quién se dirige cuando emplea el pronombre personal "tú" escrito con mayúscula? 
libro sea posible para que exista. Sólo queda excluido lo imposible"36. De manera indirecta se entiende que si bien la "Biblioteca" tiene "(...) una elegante dotación de anaqueles, de tomos enigmáticos", muchos de los cuales se creyeron "libros impenetrables" escritos en "lenguas pretéritas o remotas", su existencia era un hecho aun cuando su lectura, por algún motivo, fuera inviable.

Sobre esta tesis asienta la certeza que desde tiempo inmemorial "un bibliotecario de genio" 37 descubrió la ley fundamental de la "Biblioteca" y ésta es la siguiente: "(...) todos los libros por diversos que sean, constan de elementos iguales: el espacio, el punto, la coma, las veintidós letras del alfabeto" 38 , con lo cual señala a una cierta legalidad no declarada, pero si descubierta por aquel (o aquellos) bibliotecario (s) de genio que - por el contexto- bien pudo haber sido el mismo Borges.

De manera simultánea, el astuto bibliotecario descubrió que "No hay en la vasta Biblioteca, dos libros idénticos"39. Cada uno de ellos está escrito en caracteres peculiares, propios, incluso criptográficos en su singularidad, pero no por ello carentes de aquellos elementos iguales anteriormente mencionados. Con ello se confirma la regularidad de la ley fundamental de la enorme "Biblioteca", que viene a contradecir "el problema que ninguna conjetura habia descifrado: la naturaleza informe y caótica de casi todos los libros" ${ }^{40}$. Entre ellos $\rightarrow$ se ve claro- existe una cierta legalidad. Aún así, existe un hecho incontrovertible: "cada ejemplar es único, irremplazable"41, conjugando en este relato la universalidad de lo que es siempre igual (esa cierta regularidad) con la individualidad propia de lo que es singular. Y con relación a la Biblioteca Total, es ésta tan enorme, "(...) que toda reducción de origen humano resulta

36 J. L. BORGES: "La Biblioteca de Babel".., p. 469.

37 J. L. Borges: "La Biblioteca de Babel"..., p. 467.

38 J. L. Borges: "La Biblioteca de Babel"..., p. 467.

39 J. L. BoRges: "La Biblioteca de Babel"..., p. 467.

40 J. L. Borges: "La Biblioteca de Babel"..., p. 468.

41 J. L. Borges: "La Biblioteca de Babel”..., p. 469. 
infinitesimal"42. Textos como éste en la pluma de Borges, expresan nítidamente una declaración de principios; una cierta posición dentro de su cosmovisión poético-filosófica.

Atendiendo a estas premisas, el sabio bibliotecario dedujo que la Biblioteca Total y sus anaqueles "(...) registran todas las posibles combinaciones de los veintitantos símbolos ortográficos (...) o sea todo lo que es dable expresar: en todos los idiomas"43. Todo, absolutamente todo: " $(\ldots)$ la historia minuciosa del porvenir, las autobiografias de todos los arcángeles, el catálogo fiel de la Biblioteca, miles y miles de catálogos falsos (...) la versión de cada libro a todas las lenguas, las interpolaciones de cada libro en todos los libros, el tratado que Veda pudo escribir (y no escribió)" 44 etc.

Con ello podría proclamarse que "(...) la Biblioteca abarcaba todos los libros"45, y con eso la existencia del universo "estaba justificada" 46 en el sentido de que ningún misterio o secreto podría permanecer ignorado considerando el Tiempo Total, es decir, la Eternidad. Para Borges es esta una de las claves teóricas para la inteligibilidad de su discurso que bascula continuamente entre el tiempo y la eternidad. Es ésta, sin embargo, una eternidad sui generis no acabada suficientemente de explicar, de tipo principial, originada, no originaria ni plenamente actual ${ }^{47}$. Tal vez debido a que concibe la eternidad desde el discurso humano, como una posibilidad abierta, perfectamente pensable, que surge de la consideración del presente,

\footnotetext{
42 J. L. Borges: "La Biblioteca de Babel"..., p. 469.

43 J. L. Borges: "La Biblioteca de Babel"..., p. 467. El subrayado es mío.

44 J. L. Borges: "La Biblioteca de Babel"..., p. 467.

45 J. L. Borges: "La Biblioteca de Babel"..., p. 468.

46 J. L. Borges: "La Biblioteca de Babel"'.., p. 468.
}

47 Ello no indica que Borges haya ignorado la esencia de la etemidad. El siguiente texto lo desmiente: "Los manuales de teología no se demoran con dedicación especial en la eternidad. Se reducen a prevenir que es la intuición contemporanea y total de todas las fracciones del tiempo (...). Suelen copiar esta definición de Boecio: Aeternitates est interminabilis vitae tota et perfectio possessio, y me agrada más en la casi voluptuosa repetición de Hans Lassen Martensen: Aeternitatis est (...) immediate et lucida fruitio rerum infinitarum", en "Historia de la eternidad", OC I, p. 361 . 
pero no del inabarcable presente de la eternidad, sino del tiempo humano. Pensemos en la alusión que hace de las Reflexiones de Marco Aurelio. Concebirlo de otra manera sería platonismo ${ }^{48}$. Su discurso, sin embargo, es aquí muy oscilante. Su metáfora del espejo es una buena muestra de ello porque remite inmediatamente a un mundo reflejado en el espejo y, por tanto, no real. Este sería el "otro tiempo", el tiempo humano, el "reflejado en el espejo" que abre por siempre la posibilidad, de que cualquier libro de la inmensa "Biblioteca" sea consultado por el bibliotecario imperfecto. Aun aquello escondido, esperando con ello "(..) la aclaración de los misterios básicos de la humanidad: el origen de la Biblioteca y del tiempo" 49 .

Ante esta radical esperanza fundada en esa pristina inquisición, la respuesta de Borges parece ser la perplejidad, que se traduce en la exclamación seca, categórica, indicativa de que no puede avanzar más allá de lo que ha indagado en su búsqueda incesante de las claves secretas y más profundas de lo existente que le llevan a expresar: "quiero rememorar algunos axiomas" 50.

"El primero: la Biblioteca existe ab aeterno" 51 , es decir, desde una dimensión diferente al tiempo, con lo que vuelve a plantear el problema de la eternidad o la temporalidad del mundo, revisado ya en la antiguedad y por otros eminentes filósofos de diversas épocas hasta nuestros dias ${ }^{52}$. $Y$ es que la eternidad en sentido absoluto,

48 En la "Historia de la eternidad", pp. 355-356 escribe: "Una prolija discusión del sistema platónico aquí es impensable, pero no ciertas advertencias de intención propedéutica. Para nosotros, la última y más firme realidad de las cosas es la materia - los electrones giratorios que recorren distancias estelares en la soledad de los átomos".

49 J. L. BORGES: "La Biblioteca de Babel"..., p. 468.

50 J. L. Borges: "La Biblioteca de Babel"..., p. 466.

51 J. L. BoRges: "La Biblioteca de Babel"..., p. 466.

52 Menciono aquí algunos ejemplos conocidos por todos: los textos platónicos y aristotélicos son tributarios de la eternidad del universo (cfr. Timeo y De Coelo entre otros); el pensamiento cristiano, en cambio, distingue muy bien entre tiempo y eternidad, entre Dios y el mundo (ctr. particularmente De Civitate Dei; Confesiones; De Potentia, q. 3, Suma Teológica, I, q. 44-46, etc.). En el mundo moderno y 
como sostiene la filosofia clásica y cualquier pensamiento radicalmente metafisico, no tiene principio ni fin porque está exenta de sucesión y de término; se define interminable porque el término afecta a ambos extremos, es decir, al principio y al fin ${ }^{53}$. ¿Es éste el caso del universo borgiano? No lo aclara suficientemente, al menos en esta narración, pero atendiendo a las nociones anteriormente mencionadas, la eternidad que se trasluce en su pensamiento, implica un origen, con lo cual indica un principio que no correspondería desde ningún punto de vista a la noción de eternidad expresada en sentido absoluto. Se vuelve a presentar así, de nueva cuenta, la paradoja borgiana.

De este primer axioma: "la Biblioteca existe ab aeterno", Borges apunta un primer corolario que es "la eternidad futura del mundo". Veamos el texto: "De esa verdad cuyo corolario inmediato es la eternidad futura del mundo, ninguna mente razonable puede dudar" 54 . Y no se puede dudar, porque como sostiene Borges "El hombre, el imperfecto bibliotecario, puede ser obra del azar o de los demiurgos malévolos; el universo, con su elegante dotación de anaqueles, de tomos enigmáticos, de infatigables escaleras parả el viajero y de letrinas para el bibliotecario sentado, sólo puede ser obra de un dios" 55 , de nadie más. Para reforzar dicha idea emplea una analogía: "Para percibir la distancia que hay entre lo divino y lo humano, basta comparar estos rudos símbolos que mi falible mano garabatea en la tapa de un libro, con las letras orgánicas del interior: puntuales, negrísimas, inimitablemente simétricas" $\$ 6$.

Lo escrito en la tapa del libro, lo pueden constituir los inumerables ensayos, poemas y cuentos que Borges escribió, tomando como tema algún tópico por él descubierto en la Biblioteca Total; o sea, el

contemporaneo encontramos estudios como los de Leibniz y Kierkegaard que justifican la aspiración a la eternidad que proyecta vitalmente el ser humano (cfr.

Teodicea, El concepto de la angustia), etc.

${ }^{53}$ Cfr. S. T. Aquino: S. Th., q. 10, a. 1, resp.

54 Cfr. J. L. Borges: "La Biblioteca de Babel”..., p. 466.

55 J. L. Borges: "La Biblioteca de Babel"..., p. 466.

56 J. L. Borges: "La Biblioteca de Babel"..., p. 466. 
universo, sin ningún tipo de reserva. Por ello le fue posible afirmar, y aquí hago una glosa de su idea, "si algo es posible, es expresable en cualquier idioma", sea el lenguaje simbólico de la poesía, el riguroso y argumentado de la filosofia, el analógico de la mística o el simple, pero no por ello menos importante, lenguaje ordinario. El libro - por otro lado- puede ser aquel "libro circular de lomo contínuo" que -recordémoslo- es Dios: "Ese libro cíclico es Dios" 57 , con lo cual cabe establecer la diferencia-distancia entre lo divino y lo humano. $\mathrm{El}$ asunto, sin embargo, es problemático tomando en cuenta la obra total de Borges.

El segundo de los axiomas tiene que ver con la Ley Fundamental de la "Biblioteca": "El número de símbolos ortográficos es veinticinco" 58 , no más ni tampoco menos. En este número exacto quedan incluidos el punto, la coma, el espacio y las veintidós letras del alfabeto. Con ellos es suficiente para enumerar, describir, ponderar y posibilitar lo desconocido, en virtud de que cualquier escrito que los contenga "puede" existir. En el universo borgiano sólo "queda excluido lo imposible" y esta afirmación vale tanto para su universo literario y poético como para su cosmovisión personal que, al menos en esta narración, es siempre optimista dentro de sus paradojas y enigmas no resueltos.

Pero el no resolverlos no es indicativo de que para siempre permanezcan en la sombra. En Borges “(...) es verosímil que esos graves misterios puedan explicarse en palabras: si no basta el lenguaje de los filósofos, la multiforme Biblioteca habrá producido el idioma inaudito que se requiere y los vocabularios y gramáticas de ese idioma"59. En Borges sólo es inexpresable lo imposible, lo escrito en un lenguaje asaz incomprensible como puede ser la fórmula "dhcmrlchtdj"60, que de suyo no indica, no hace referencia, no comunica nada. En efecto, para él "(...) la Biblioteca incluye todas las estructuras verbales, todas las variaciones que permiten los

57 J. L. Borges: “La Biblioteca de Babel”..., p. 466.

58 J. L. BorGEs: "La Biblioteca de Babel".., p. 466

59 J. L. Borges: "La Biblioteca de Babel",.., p. 468

60 J. L. Borges: "La Biblioteca de Babel"..., p. 470 
veinticinco símbolos ortográficos, pero no un solo disparate absoluto"61, quiero decir con ello algo imposible.

Un último texto al respecto:

"Lo repito: basta que un libro sea posible para que exista. Sólo está excluido lo imposible. Por ejemplo: ningún libro es también escalera, aunque sin duda hay libros que discuten y niegan y demuestran esa posibilidad y otros cuya estructura corresponde a la de una escalera"62.

Estas ideas me recuerdan otro texto más de Wittgenstein: "Representar en el lenguaje algo 'que contradiga la lógica' es cosa tan escasamente posible como representar en la Geometría (...) una figura que contradiga las leyes del espacio; o dar las coordenadas de un punto que no existe"63.

61 J. L. BORGES: “La Biblioteca de Babel”..., p. 470.

62 J. L. BoRges: "La Biblioteca de Babel"..., p. 469.

${ }^{63}$ Etwas "der Logik Widersprechendes" in der Sprache darstellen, kann man ebensowenig, wie in der Geometrie eine den Gesetzen des Raumes widersprechende Figur durch ihre Koordinaten darstellen; oder die Koordinaten eines Punktes angeben, welcher nicht existiert (Tractactus logico-philosophicus 3.032). 
Copyright of Tópicos. Revista de Filosofía is the property of Universidad Panamericana and its content may not be copied or emailed to multiple sites or posted to a listserv without the copyright holder's express written permission. However, users may print, download, or email articles for individual use. 